\title{
Turbulence intensity and spatial scales of turbulence after hydraulic jump over scour hole in rectangular channel
}

\author{
Adam Kozioł $^{1 *}$, Janusz Urbański ${ }^{1}$, Adam Kiczko ${ }^{1}$, Marcin Krukowski ${ }^{1}$, Piotr Siwicki ${ }^{1}$, Marek Kalenik $^{2}$ \\ ${ }^{1}$ Department of Hydraulics, Faculty of Civil and Environmental Engineering, Warsaw University of Life Sciences - SGGW, Warszawa, \\ Poland. \\ ${ }^{2}$ Department of Civil Engineering, Faculty of Civil and Environmental Engineering, Warsaw University of Life Sciences - SGGW, \\ Warszawa, Poland. \\ * Corresponding author. Tel.: +48 225935276. E-mail: adam_koziol@sggw.pl
}

\begin{abstract}
The study presents experimental investigations of spatial turbulence intensity and scales of turbulent eddies (macroeddies) in a rectangular channel and the impact of the hydraulic jump on their vertical and streamwise distributions over a flat and scoured bed. The results of four tests and two different discharge rates are presented. Intensive mixing caused by the hydraulic jump has an impact on the instantaneous velocity, turbulence intensity and sizes of macroeddies, as well as their vertical and longitudinal distributions along the channel. The largest differences in turbulence characteristics were reported directly after the hydraulic jump, above the eroded bed. The interaction between the stream of the increased turbulence and the bed is a direct cause of formation of scour downstream water structures, which has a great effect on overall flow characteristics. The scour hole that arose downstream the jump moderated, in a small degree, the turbulence intensity at its end. Just next to the hydraulic jump only the small longitudinal relative sizes of macroeddies were present, while at the end of the analyzed reach, downstream of the scour, the relative scale reached around 1.5 depth of the stream.
\end{abstract}

Keywords: Turbulent intensity; Eddies; Hydraulic jump; Scour hole; Rectangular channel.

\section{INTRODUCTION}

The water structures, especially the outflow devices built in open channels, often force the transition from the supercritical to subcritical flow regimes, which results in formation of a hydraulic jump. This phenomenon is characterized by an intensive turbulent mixing with the increased instantaneous velocities near the bed. As a result of it the stream reveals highly eroding potential, especially with regard to fine particle soils. The flowing water detaches the bed and transports it leading to a development of a scour hole (Ali et al., 2014; Dargahi, 2003; Oliveto and Comuniello, 2009; Pagliara et al., 2008; Urbański, 2008; Urbański, 2010). The increased turbulence at the bed is the direct cause of scour holes downstream the water structures. A kinematic complexity of the flow field depends on the construction of water structures.

As the previous studies have revealed the turbulence intensity and velocity near the bed decrease with the distance from the hydraulic jump (Kališ, 1961; Kumin, 1956; Liu et al., 2004; Urbański, 2006; Wu and Rajaratnam, 1996). Flow structures inducing hydraulic jumps intend to dissipate the total energy of the flow by provoking turbulence, dissipating it. In a reinforcement section of the outflow channel the stream is still characterized by increased turbulence. In consequence, there is the intensification of erosion of the river bed, including formation of scour holes immediately downstream water structures.

The dynamics of the scouring of the bed material depends on the kinematic structure of the flow field within the hydraulic jump. There were various attempts to identify turbulent flow characteristics over the scouring bed. Measurements of the instantaneous variation of the velocity components below scour holes are difficult and require appropriate, high-precision instruments. In addition, during the experiment the bed elevation and shape change and thus the characteristics of the flow in the scouring zone. Because of the unsteady hydraulic conditions, it is impossible to maintain the stationarity and ergodicity of the velocity field. Only experiments with the perpetuation of the bed shape in phases of scouring could allow for an identification of the kinematic structure of the shaping stream. Such studies, however, are cumbersome and time-consuming and there is a lack of a literature material in this subject.

An open channel flow is, by nature, three-dimensional. The turbulence intensity is one of the most important characteristics of a turbulent water flow, being defined in all three directions from the velocity data as follows:

$u^{\prime}=\sqrt{\overline{\overline{u^{2}}}}, \quad v^{\prime}=\sqrt{\overline{v^{2}}}, \quad w^{\prime}=\sqrt{\overline{\overline{w^{2}}}}$

where $u, v$ and $w$ - the velocity fluctuations in streamwise, lateral, and vertical directions, respectively. However, many researchers prefer the relative turbulence intensity given by $u^{\prime} / U, v^{\prime} / U$, and $w^{\prime} / U$, where $U$ is the time-averaged point velocity in the streamwise direction $(\mathrm{x})$. In this paper, the turbulence intensity for the streamwise and lateral directions is presented.

Nezu and Nakagawa (1993) proposed the equations describing relative turbulence intensity distributions in single channels for a steady and uniform 2D flow. However, the conditions of water flow after a water plant or in a compound channel are significantly different and very complex (Ali et al., 2014; Czernuszenko et al., 2007; Dargahi, 2003; Kozioł, 2013, 2015; Kozioł and Kubrak, 2015; Kozioł et al. 2016; Mazurczyk, 2007; Nezu and Nakagawa, 1993; Nikora et al., 1994; Oliveto and Comuniello, 2009; Oliveto et al., 2011; Pagliara and Palermo, 2013; Rowiński et al., 1998; Rowiński et al., 2002; Shiono and Knight, 1991; Siniscalchi et al., 2012). The turbulence generation produces fluctuations of the flow velocity associated with big vortices, and the turbulent energy is converted into an energy cascade to smaller scale eddies until it is dissipated into heat 
by the molecular viscosity (Nezu and Nakagawa, 1993). Nikora (2007) presented an interpretation of how the flow energy is distributed through temporal and spatial scales present in fluvial systems. River dynamics is characterized by a wide range of scales, which may vary from seconds to years (or even centuries), in terms of time, and from $\mathrm{mm}$ to $\mathrm{km}$ in terms of spatial dimensions (Franca and Brocchini, 2015). River flows are characterized by a large variety of space scales, which are impermanent. The eddies (macroeddies) are disintegrated into structures of smaller sizes (microeddies, e.g., Kozioł, 2012), but simultaneously new, large structures are generated. As a result, the whole and continuous range of sizes of eddies exists in the flow. The scales of eddies in flows are crucial for determining sediment transport and deposition, bed formation and other processes in rivers.

The external scale of turbulence is determined by the sizes of macroeddies. Evaluation of their size must be preceded by the determination of time-scales of macroeddies on the basis of an Eulerian framework of measurements. To this end, autocorrelation functions $R(t)$ can be used for this evaluation. The functions exhibit very similar forms of decaying curves with an alteration of the domains of the positive and negative values. A normalized autocorrelation functions $R(t)$ between two streamwise velocity components $u(x)$ and $u(x+t)$, with a streamwise lag distance $t$, is defined as follows (Czernuszenko and Holley, 2007):

$$
R_{x}(t)=\frac{\overline{u(x) \cdot u(x+t)}}{\overline{u^{2}}}
$$

Basing on autocorrelation functions, Euler time-macroscales $T_{E}$ are derived according to (Nikora et al., 1994):

$$
T_{E}=\int_{0}^{\infty} R_{x}(t) d t
$$

which are a measure of the slowest changes in the turbulent flow caused by macroeddies. For a steady and uniform turbulent flow, when the mean velocity in a given point significantly exceeds the velocity of fluctuations, there exists, according to the Taylor's hypothesis, a direct relationship of temporal and spatial Eulerian autocorrelation functions. Referring to Taylor's relationships between the temporal $T_{E}$ and spatial $L$ turbulence macroscale, the following formula for mean longitudinal sizes can be derived:

$$
L=U T_{E}
$$

Most often the sizes of macroeddies are related to the water depths $(h)$ in an analyzed measurement vertical for easier comparison. According to Nikora et al. (1994), the spatial scales ranging from $L / h=0.1$ to the scales on the order of twice or even three times the depths of the stream and results agree closely with the measured data of Yokosi (1967), McLean and Smith (1979), Nikora (1985) and Grinwald and Nikora (1988). In open channels, for different roughness of the channel without and with vegetated floodplains, the variability of macroeddies was analyzed in the research papers: Rowiński et al. (2002), Rowiński and Mazurczyk (2006), Czernuszenko et al. (2007), Mazurczyk (2007), Kozioł (2000, 2008, 2015), Kozioł and Kubrak (2015).

This paper presents the analysis of the turbulence intensity and spatial scales of turbulence (macroeddies) distributions on length of stream after the hydraulic jump, calculated basing on the measurements of instantaneous water velocities in a rectangular channel. Instantaneous velocities of water in streamwise and lateral direction were measured in centerline of the channel, over a horizontal bed and scoured bed, for four tests with two different discharges. The used measuring data come from earlier investigations of relating lengths of protection and the scour of bed (e.g. Urbański, 2006, 2012). Preliminary results for three different discharges in the channel with a flat and horizontal bed were provided by Kozioł et al. (2016).

\section{EXPERIMENTAL SETUP AND PROCEDURE}

The experiments considered herein were carried out in a hydraulic laboratory with the sluice gate model (Fig. 1). The laboratory flume was rectangular with a width $(b)$ of $1 \mathrm{~m}$. The model consisted of a weir with the flat sluice gate, a stilling basin with the reinforced bed section (transition region) and a sand bed section. The gate opening allows to control the headwater $(H)$ level in the upper stand. The tailgate maintains a desired water level at the flume end. The discharge $(Q)$ remains constant during each tests. The transition from the supercritical to subcritical flow induces the formation of the jump, takes place due to a contraction of the stream at the sluice gate opening height $(a)$. The hydraulic jump was submerged and forced in the stilling basin. The bed, on the length of $0.5 \mathrm{~m}$ below the stilling basin, was reinforced with a cement concrete (Fig. 1), farther downstream it consisted of fine sands of $d_{50}=$ $1.1 \mathrm{~mm}$ (sediment gradation coefficient $\sigma=1.77$ ).

In this paper, two experiments for different flow rates and corresponding water depths in the upper and lower stands (Fig. 1) were performed. The hydraulic conditions for each experiment are given in the Table 1: discharge $(Q)$, times of scour $(t)$, tailwater depth $\left(h^{\prime}\right)$, upstream depth $(H)$, and the gate opening $(a)$, calculated supercritical $\left(h_{1}\right)$ and $\left(h_{2}\right)$ subcritical depths, and supercritical Froude number $F_{r l}=U_{a}(g a)^{-1 / 2}$, where $U_{a}$ denotes the supercritical approach velocity, $g$ is the acceleration due to gravity. The experiments were performed in two stages. In the first the measurements were taken over the stabilized with a lacquer, non-eroded sand bed (test 1 and 2, Fig. 1, Table 1). In the second, for same boundary conditions like in the first stage, a bed was allowed to erode (test 1.1 and 2.1, Fig. 1, Table 1). After $t=480$ minutes the scouring process was stopped, it was a nearly-equilibrium phase in which the dimensions of the scour hole no longer change significantly, and the bed geometry, including a shape of the scour hole, was measured. Then the bed surface was stabilized with a lacquer, to obtain a non-erodible surface. Hydraulic measurements were repeated for such a scoured bed, with the same discharge $(Q)$ as previously. The experiment setup was as follows: in the test 1.1 $(Q=73 \mathrm{l} / \mathrm{s})$ maximum scour depth was $0.15 \mathrm{~m}$ at a distance of $x$ $=0.45 \div 0.5 \mathrm{~m}$ from the reinforced bed, and in the test $2.1(Q=$ $97 \mathrm{l} / \mathrm{s}$ ) maximum depth was $0.22 \mathrm{~m}$ at a distance $x=0.75 \div 0.8$ $\mathrm{m}$. In the second test, with the highest discharge, the flume was scoured at the entire length. Urbański (2008) provided the detailed information on the scouring dynamics of the current experiment.

The flow field was investigated with velocity measurements taken in the centerline of the flume, for a different distance from the reinforced bed (Fig. 1). Depending on the test, 9 to 16 verticals of instantaneous velocity were taken. Each vertical consisted of four measurement points at depths arranged as follows: the bed at $z_{l}=0.018 \mathrm{~m}, z_{2}=0.3 h, z_{3}=0.6 h$ and just below the water surface level $z_{4}=h-0.02 \mathrm{~m}$, where $h$ denotes the local water depth (Fig. 1). The number of measurement verticals and points depended on a scouring length. 
Table 1. The hydraulic parameters of flow during of experiments.

\begin{tabular}{|c|c|c|c|c|c|c|c|c|}
\hline \multirow{2}{*}{ Test } & $Q$ & $t$ & $h^{\prime}$ & $H$ & $a$ & $h_{1}$ & $h_{2}$ & $F r_{1}$ \\
\hline & {$[1 / \mathrm{s}]$} & {$[\mathrm{min}]$} & {$[\mathrm{m}]$} & {$[\mathrm{m}]$} & {$[\mathrm{m}]$} & {$[\mathrm{m}]$} & {$[\mathrm{m}]$} & {$[-]$} \\
\hline 1 & \multirow{2}{*}{73} & 0 & \multirow{2}{*}{0.165} & \multirow{2}{*}{0.445} & \multirow{2}{*}{0.049} & \multirow{2}{*}{0.03} & \multirow{2}{*}{0.175} & \multirow{2}{*}{2.15} \\
\hline 1.1 & & 480 & & & & & & \\
\hline 2 & \multirow{2}{*}{97} & 0 & \multirow{2}{*}{0.193} & \multirow{2}{*}{0.462} & \multirow{2}{*}{0.065} & \multirow{2}{*}{0.04} & \multirow{2}{*}{0.201} & \multirow{2}{*}{1.87} \\
\hline 2.1 & & 480 & & & & & & \\
\hline
\end{tabular}
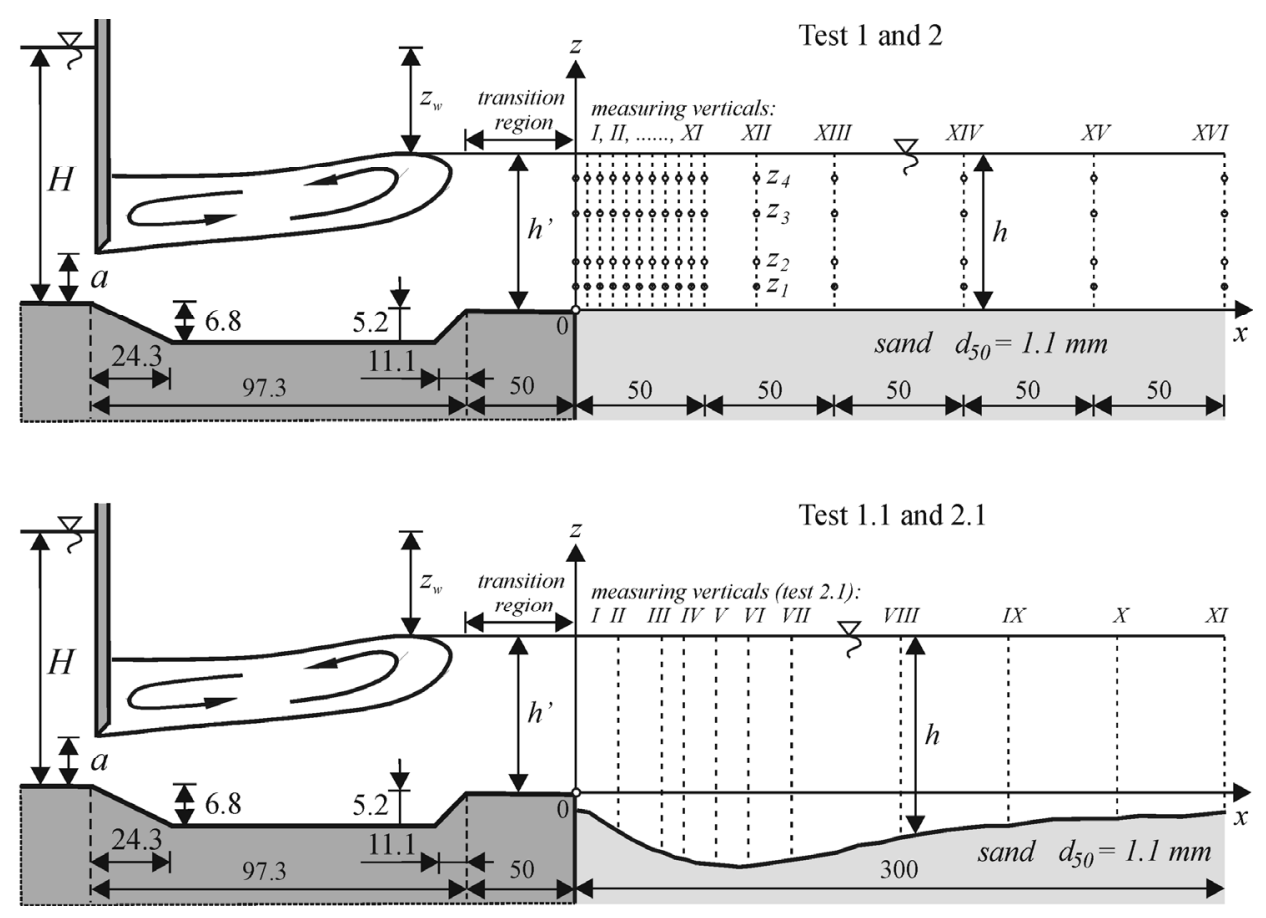

Fig. 1. Schema of investigated model and basic dimensions (dimensions in $\mathrm{cm}$ ).

In this study, instantaneous streamwise and lateral velocities were measured with the use of the programmable electromagnetic liquid velocity meter 2D PEMS manufactured by Delft Hydraulics. The meter proved to yield a good description of the turbulence characteristics when certain conditions related to the flow itself and the configuration of the instrument were satisfied (Buffin-Bélanger and Roy, 2005). The measurements were conducted with the maximum frequency of $10 \mathrm{~Hz}$ in the velocity range of $0-1.0 \mathrm{~m} / \mathrm{s}$ with an accuracy of $\pm 0.01 \mathrm{~m} / \mathrm{s}$ (sampling volume $0.25 \mathrm{cc}$ ). A sampling duration of $120 \mathrm{~s}$ was determined from initial tests to be adequate to obtain stationary turbulence statistics and was therefore used. Buffin-Bélanger and Roy (2005) report that, for most turbulent statistics, a sufficient record length for the measurements is 60-90 s. In case of our experiments, even longer time series were recorded to provide reliability of data and constant character of higher-order velocity moments. The measured velocity field was obviously of a stochastic nature and the stationarity and ergodicity of the process was checked.

\section{RESULTS AND DISCUSSION Velocity profiles}

Figures 2(a-c) present the changes of streamwise velocities $U$ as a function of the relative depth $z / h$ on length of a stream $x$ after the hydraulic jump for four tests. The conducted tests 1.1 and 2.1 provided information on streamwise velocities for the scoured bed at the time of $t=480 \mathrm{~min}$. Downstream of the hydraulic jump the longitudinal velocity distributions with a depth were different from shapes found in open channels. The velocity distributions changed with a stream length, that was the most noticeable for larger depths [tests 2 and 2.1, Fig. 2(ac)]. After the hydraulic jump the maximum longitudinal velocity was observed near the bed, while the lowest near the water surface, that results from the flow structure of the jump - the presence of a backflow at the water surface. Directly downstream the stilling basin the increased bed velocity caused bed scouring. The experiment showed the shift of the maximum velocity in a vertical profile from the bed near the hydraulic jump toward the water surface with the increasing distance. This is typical for a so-called transitional zone (Wu and Rajaratnam, 1996) between the jump and the normal openchannel flow. The velocity distribution similar to a normal open channel condition was found here at the distance about $x / h=$ 1.5. The presented results and previous studies of Urbański (2012) allow stating that the distance from the hydraulic jump required to form the velocity distribution of the open channel with the free flow conditions depends on the hydraulic properties of the jump and the depth of the outflow.

The scour hole (tests 1.1 and 2.1) affected the streamwise velocity distribution with depth. Like in a flow over non-eroded bed (tests 1 and 2) the velocity near the surface generally increased with the distance from the jump, it is however different at the scoured area. At the maximum depth point (for $Q=73 \mathrm{l} / \mathrm{s}$, $x=0.45 \div 0.5 \mathrm{~m}$, whereas for $Q=971 / \mathrm{s}, x=0.75 \div 0.8 \mathrm{~m})$ the surface velocity falls till the end of the scour hole, where again it starts to increase. Immediately downstream of the hydraulic jump, for scoured bed tests, the maximum longitudinal velocity was observed at the depth $z / h=0.36$ and from this point was shifted with the distance towards the water surface (Fig. 2). 

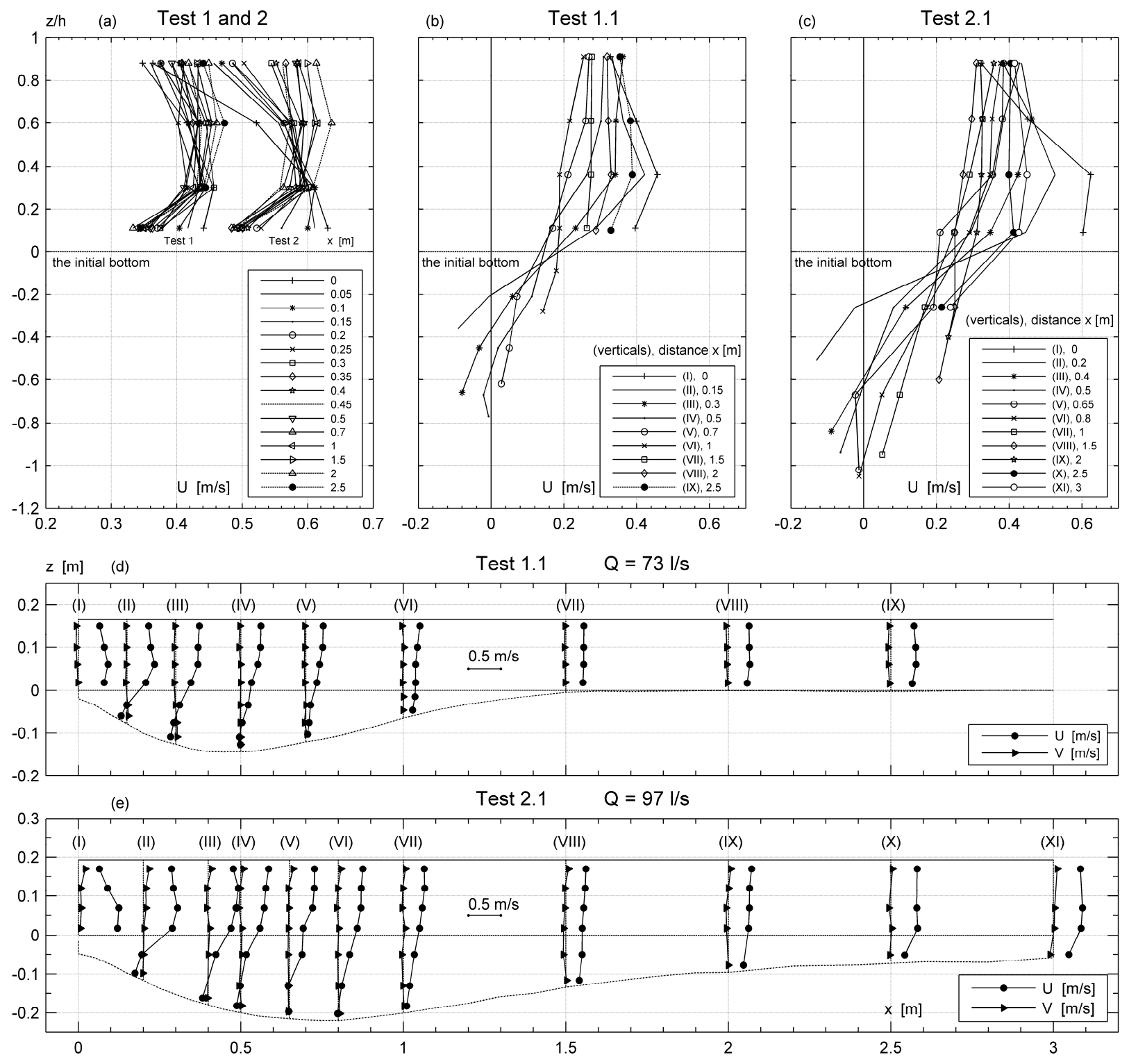

Fig. 2. Vertical profiles of streamwise velocities $U$ after the hydraulic jump for four tests.

Near the water surface the streamwise velocity reached its maximum value for about half of distance between the beginning of the scoured reach and its maximum depth point and maintained it till the end of a small scour in the test $1.1(x=$ $1.5 \mathrm{~m})$ within the sour hole in the test $2.1(x=2 \mathrm{~m})$. The results indicate that above the scoured bed there is the region of the reversed flow, which supports findings of other studies in this field (e.g. Dargahi, 2003). Such a region could be observed, from the beginning of the scour to the maximum depth point at the distance of $x=0.15 \div 0.5 \mathrm{~m}$ in the test 1.1 and $x=0.2 \div 0.8 \mathrm{~m}$ in the test 2.2 (Fig. 2).

In all experiments the lateral velocity $V$ was considerably smaller than the longitudinal velocity $U$, with values of an order of a few centimeters per second [Fig. 3(d-e)]. The scour hole caused an insignificant increase in the lateral velocity.

\section{Distribution of turbulence intensities}

Figures $4(a-d)$ present the vertical distributions of streamwise turbulence intensity $u^{\prime}$ after the hydraulic jump for four tests. The results indicate that downstream of the hydraulic jump the highest turbulence intensities were present near the surface and turbulence intensities in streamwise direction decreased with the distance of the jump. Before development of scour, in tests 1 and 2 , the streamwise turbulence intensity decreased from the water surface towards the bed, and from the relative depth $z / h=0.6$ values remained constant. In initial stages of both tests ( 1 and 2$)$ the streamwise turbulence intensity distributions were the same and differences emerged after formation of the scour hole (tests 1.1 and 2.1).

At the section between the beginning of the scour hole and its highest depth point (in test 1.1 on length $x=0.15 \div 0.5 \mathrm{~m}$ and in test 2.1 for $x=0.2 \div 0.8 \mathrm{~m}$, Fig. 3), the streamwise turbulence intensity decreased from the water surface toward the bed up to depth of $z / h=0.6$, downwards the intensity increased till the $z / h$ $=0.1$ when again it decreased while getting closer to the bed. The peak in $u^{\prime}$ values at the depth of $z / h=0.1$ and later fading of this maximum come from the shift of the maximum longitudinal velocity $U$ towards the water surface with the distance from the hydraulic jump (Fig. 2). Downstream the maximum depth point of the scour hole the $u^{\prime}$ decreased from the water surface to the bed in the entire vertical (Fig. 3). 

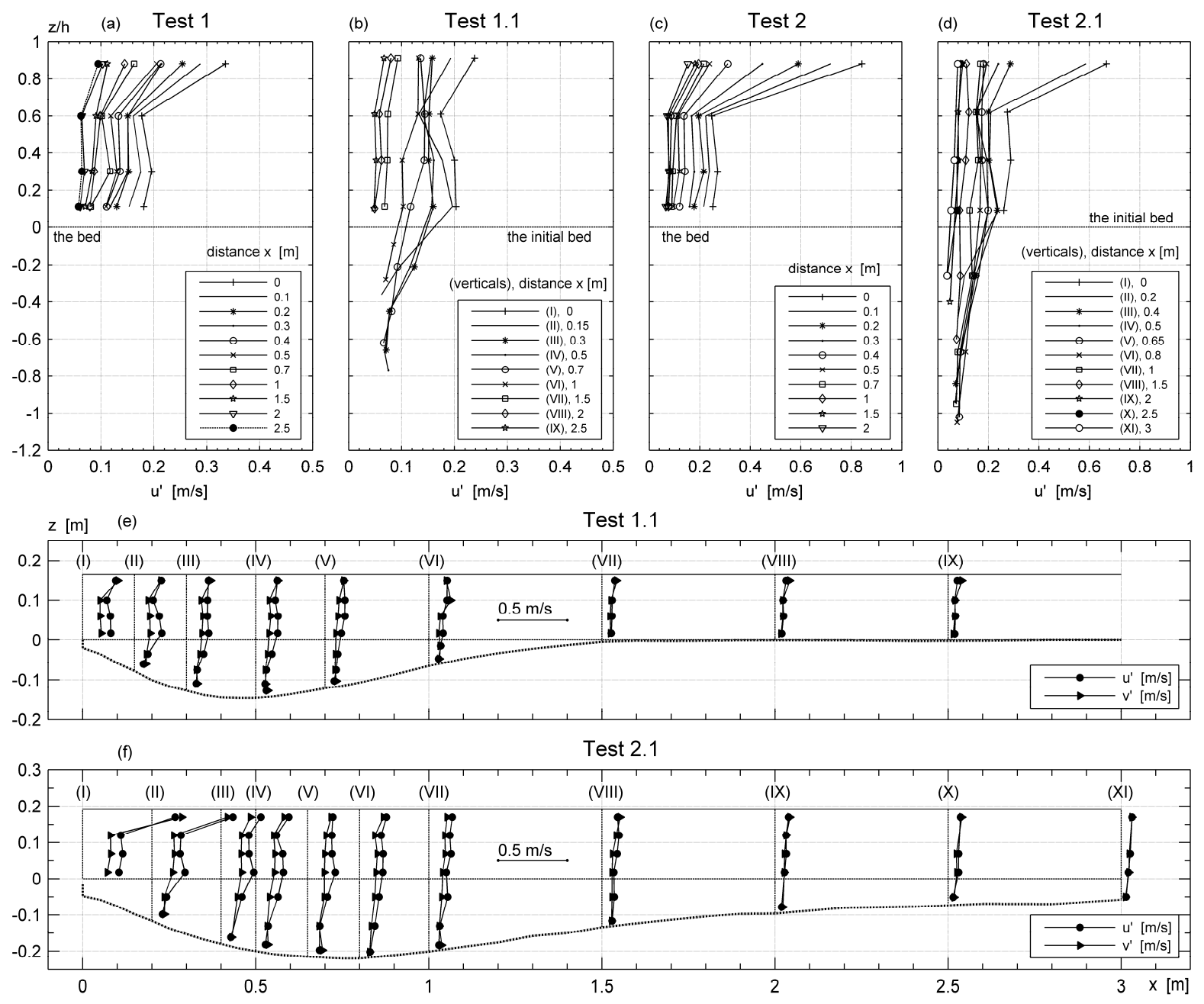

Fig. 3. Vertical distributions of turbulence intensities $u$ ' and $v^{\prime}$ for tests $1,1.1,2$ and 2.1.

In the measurement profiles farther from the hydraulic jump the turbulence intensity in the streamwise direction decreased with the deep or remained constant [Fig. 4(a-d)], which means that acquired distributions are different from those described by Nezu and Nakagawa (1993) for the open channels. Generally, streamwise turbulence intensity values are rising from the water surface towards the bed (e.g., Koziol, 2013; Nikora et al., 1994). Distributions of the streamwise turbulence intensity measured at the end of the experimental flume do not exactly follow a shape typical for open channels, but values are already similar to these reported in literature.

In all tests, the transversal velocity $V$ is small compared to the longitudinal velocity $U$ [Figs. 2(d-e)], but the intensity of turbulence in both directions: streamwise $u^{\prime}$ and lateral $v^{\prime}$ have similar shapes [Fig. 3(e-f)]. Lateral turbulence intensity values also decreased with the distance. In tests 1 and 2 the shapes of vertical distributions of turbulence intensity $u^{\prime}$ and $v^{\prime}$ were the same and did not change with the distance. Downstream of the hydraulic jump near the water surface values of turbulence intensities $\mathrm{u}^{\prime}$ and $\mathrm{v}^{\prime}$ were the same, while below $(z / h \leq 0.6)$ lateral intensities were smaller. Farther from the hydraulic jump the lateral intensities near the water surface were smaller, but below $z / h \leq 0.6$ were equal in both directions.

It is different in the case of experiments over the scoured bed. Vertical distributions of turbulence intensities $u^{\prime}$ and $v^{\prime}$ clearly differs [Fig. 3(e-f)]. On the whole depth the lateral turbulence intensities decreased from the water surface toward the bed, and the largest decline occurred at the beginning of the scour hole, where an intensive mixing of water was still present. Over the scour hole values of $u^{\prime}$ and $v^{\prime}$ were generally similar near the water surface and the bed, but in the central zone the $v^{\prime}$ were significantly smaller [Fig. 3(e-f)]. However, near the end of the scoured hole, and farther downstream values of $u^{\prime}$ and $v^{\prime}$ were equal.

Figure 4 presents distributions of turbulence intensities in streamwise $u^{\prime}$ and lateral $v^{\prime}$ directions at the distance downstream of the hydraulic jump over the flat bed (tests 1 and 2) and over the scour hole (tests 1.1 and 2.1), for different depths. In tests 1 and 2 with the distance the biggest decline of the $u^{\prime}$ took place immediately downstream the jump for $x=0$ to $0.5 \mathrm{~m}$ and the further decline was small, which suggests that the flow was significantly stabilized. At the length $x=0$ the velocity $U$ was higher near the bottom than at the water surface $(z / h=0.9$, test 2, Fig. 2), but for the intensity $u^{\prime}$ it was opposite: its value was higher at the water surface than at the bed [Fig. 4(a)]. In test 2 the increase of the velocity led to an increase in longitudinal turbulence intensity throughout the depth for the beginning of the analyzed reach $(x=0 \div 0.5 \mathrm{~m})$ and farther only near the water surface. The high values are found immediately downstream of the hydraulic jump and above the initial bed level. Downstream of the locations of the high values, the turbulence intensities are damped, as the distance from the hydraulic jump increases. It is important to note that the positions where the high values of turbulence intensities occur are found at the end of the recirculation zone of the hydraulic jump. 
(a)

Test 1 and $2, \quad z / h=0.1$ and 0.9

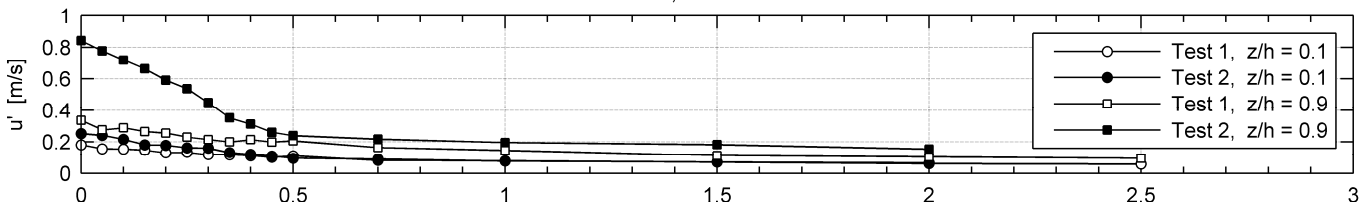

(b)

Test 1.1 and 2.1, $\mathrm{z} / \mathrm{h}=0.9$

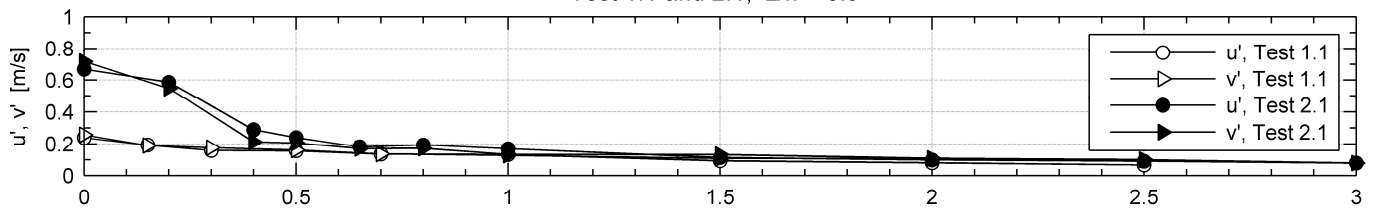

(c)

Test 1.1 and $2.1, \mathrm{z} / \mathrm{h}=0.1$

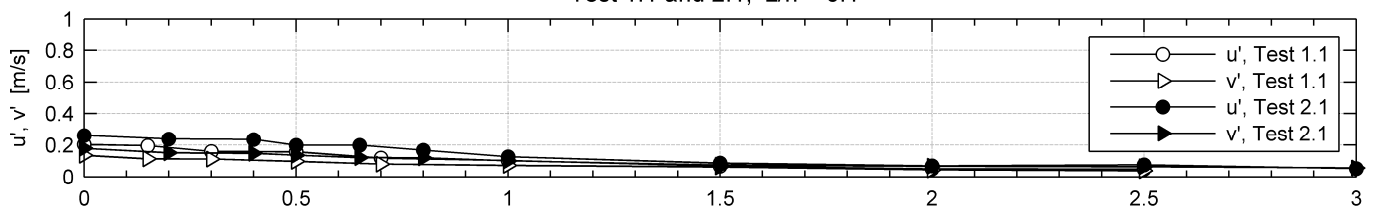

(d)

Test 1.1 and 2.1, at the bed

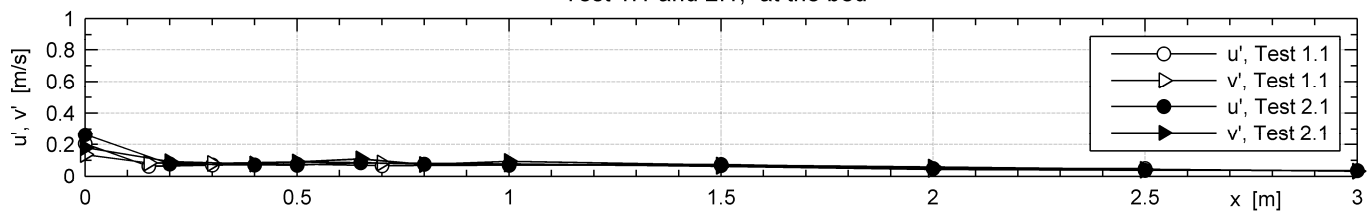

Fig. 4. Distributions of turbulence intensities in streamwise $u^{\prime}$ and lateral $v^{\prime}$ directions on length of stream after the hydraulic jump over the flat bed (tests 1 and 2) and over the scour hole (tests 1.1 and 2.1).

Above the hole, the biggest decline in the values of $u^{\prime}$ and $v^{\prime}$ took place immediately downstream the jump near the water surface $(z / h=0.9)$ for the higher discharge rate [Fig. 4(b)]. For the middle depths of the stream, near the initial bed line for $z / h=0.1$ [Fig. 4(c)], the values of $u^{\prime}$ and $v^{\prime}$ decreased over the entire length, and at the end of the scour hole the decrease was small. At the bed of the scour hole on a short section there was a decline in the values of $u^{\prime}$ and $v^{\prime}$, at the section from $x=0.2$ to $1 \mathrm{~m}$ values remained constant and farther both values slowly decreased [Fig. 4(d)].

For the measurement profiles ( $x=2$ to $2.5 \mathrm{~m}$ ), located farthest from the jump, turbulence intensity decreased to values in the range of 0.03 to $0.15 \mathrm{~m} / \mathrm{s}$ which corresponds to the values reported in the literature for the open channel (Czernuszenko and Lebiecki, 1980; Kozioł, 2013; Nikora, 1985; Nikora et al., 1994; Nikora and Smart, 1997; Rowiński et al., 2002; Rowiński and Mazurczyk, 2006; Sanjou et al., 2010; Shiono and Knight, 1991). On the basis of conducted experiments it can be noted that formation of the scour hole causes only a slight decrease in the turbulence intensities in the farthest measurement points downstream of the hydraulic jump. Analyzing the velocity and the turbulence intensity profiles it can be seen that the greatest changes occurred immediately downstream of the hydraulic jump at the distance of $x=0$ to $0.5 \mathrm{~m}$, where there was a strong interaction between the stream and the bed, which resulted in rapid stabilization of the flow, and with a depth near the water surface where the most intensive mixing was present due to the influence of the hydraulic jump.

\section{Spatial scales of turbulent eddies (macroeddies)}

Figure 5 presents the vertical distributions of streamwise relative sizes of macroeddies on length of stream after the hydraulic jump over the flat bed (tests 1 and 2) and over the scour hole (tests 1.1 and 2.1). The relative sizes of macroeddies are related to the depth in a vertical profile, in the tests 1 and 2 to a constant depth $\left(h \approx h^{\prime}\right)$ and in tests 1.1 and 2.1 to the depth of the eroded bed. On the basis of tests 1 and 2 it can be seen that the vertical distributions of relative sizes of macroeddies downstream of the hydraulic jump, do not depend on the discharge rate, having the same value and distribution along the stream (Fig. 5). In the first measurement profile $(x=0 \mathrm{~m})$ the smallest relative sizes of macroeddies were present near the water surface $(L / h=0.2 \div 0.6)$, rising towards the bed through the whole depth and reaching near the bed the length equal approximately to one depth of the stream. In next neighbor profiles the smallest sizes of macroeddies still characterized the water surface region, but from $z / h=0.6$ to the bed the sizes become equal to the length of one stream depth. In remaining points the relative sizes of macroeddies increased from the water surface to $z / h=$ 0.6 and then decreased towards the bed. The intensive mixing caused by the hydraulic jump resulted in creation of only short sizes macroeddies near the water surface. For the middle depths $[z / h=0.3 \div 0.6$, Fig. $5(\mathrm{a})]$ macroeddies sizes were greater because in the bed region exist the highest gradient of the mean velocity and in the water surface region intense water mixing occurs.

In tests over the eroded bed the vertical distributions of the relative sizes of macroeddies were similar and also were changing with the stream distance. In a first vertical profile $(x=0)$, as in tests 1 and 2, the relative sizes of macroeddies increased from the water surface towards the bed reaching the length of approximately one stream depth [Fig. 5(b-c)]. Over the bed of the scour hole, between its beginning and the maximum depth, the relative sizes of macroeddies increased from the water surface towards the bed but just above the initial bed line sizes decreased until the bed region where they started rising again towards the bed. In the bed region macroeddies sizes increased due to the presence of the backflow. For the vertical profile at the maximum depth of the scour hole [in test $1.1 x=0.5 \mathrm{~m}$ and 
(a)

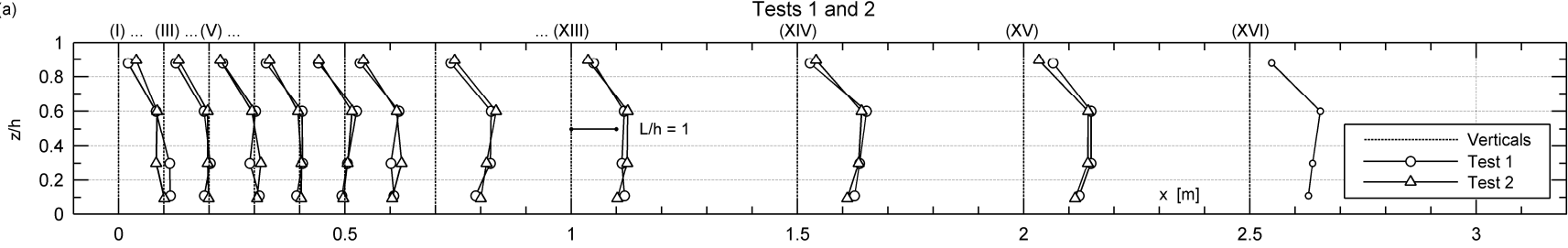

(b)

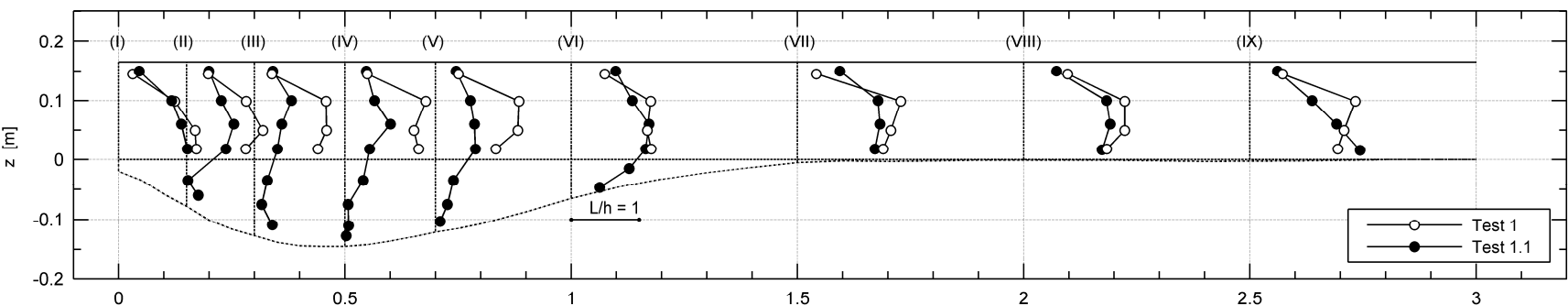

(c) Test 2.1

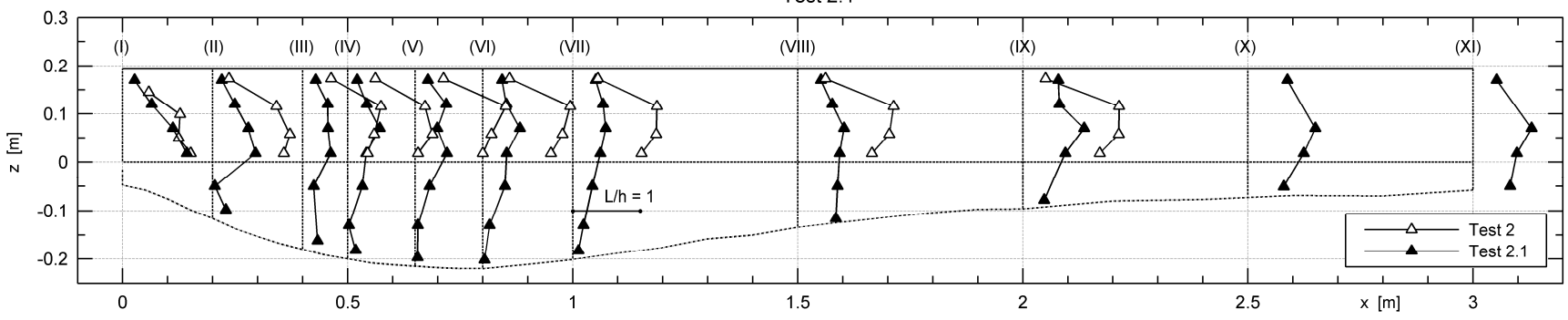

Fig. 5. Vertical distributions of streamwise relative sizes of macroeddies $L / h$.
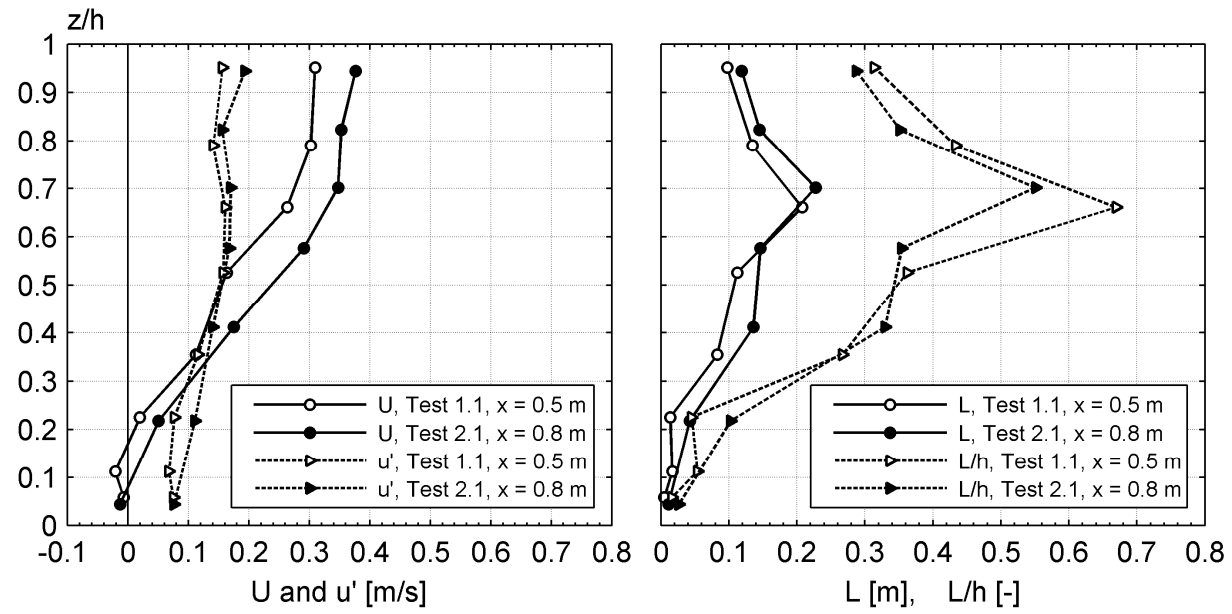

Fig. 6. Vertical distributions of streamwise velocities $U$, turbulence intensities $u$, sizes of macroeddies $L$ and relative sizes of macroeddies $L / h$ at the maximum depth of the scour hole in tests 1.1 and 2.1.

in test 2.1 for $x=0.8 \mathrm{~m}$, Fig. 5(b-c) or Fig. 6] the relative sizes of macroeddies increased from the water surface towards the bed reaching the maximum at about the $z / h=0.65$ (Fig. 6) and from that point were decreasing. In the farther profiles the vertical distributions tended to remain generally constant. Over the bed of the scour hole, it is clear that there are two regions with different vertical distributions, before and after the maximum depth of the scouring bed. The length of the first region is about $0.5 \mathrm{~m}$ in test 1.1 and $0.8 \mathrm{~m}$ in test 2.1 . Intensive mixing of waters caused by the hydraulic jump results in that the depthaveraged size of macroeddies are almost the same at the length of the scour hole in the first region, for both tests. In the second region the depth-averaged size of macroeddies increases at the end of the scour hole.
Figure 6 presents vertical distributions of streamwise velocities $U$, turbulence intensities $u$, sizes of macroeddies $L$ and relative sizes of macroeddies $L / h$ at the maximum depth of the scour hole in test $1.1[x=0.5 \mathrm{~m},(\mathrm{IV})]$ and in test $2.1[x=0.8 \mathrm{~m}$, (VI)]. With the increase of the discharge in the channel, the size of the scour hole also increases and the location of the maximum depth point is changing. The study revealed that the increasing discharge causes at the maximum depth of the scouring bed a rise in the vertical velocity, however turbulence intensities $u$ ', sizes of macroeddies $L$ and relative sizes of macroeddies $L / h$ remain almost constant in tests 1.1 and 2.1 (Fig. 6).

Figure 7 presents the distributions of streamwise relative sizes of macroeddies with the distance downstream from the hydraulic jump over the flat bed (tests 1 and 2) and over the 
(a)

$\mathrm{z} / \mathrm{h}=0.9$

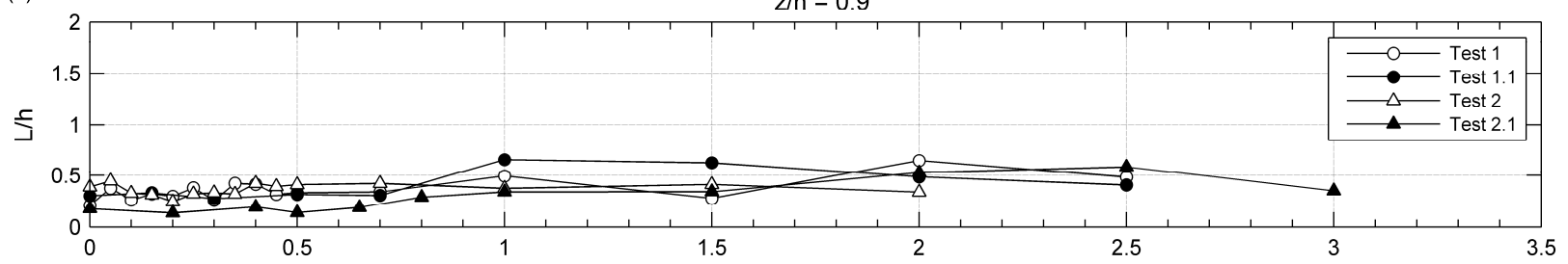

(b)

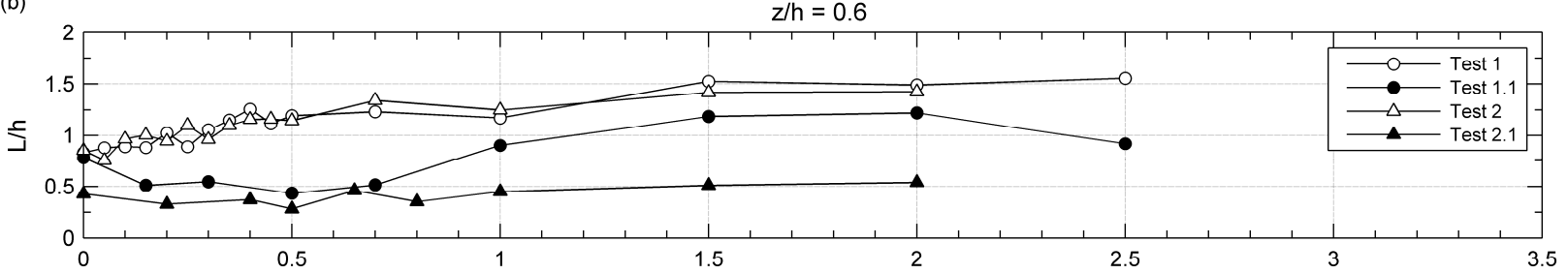

(c)

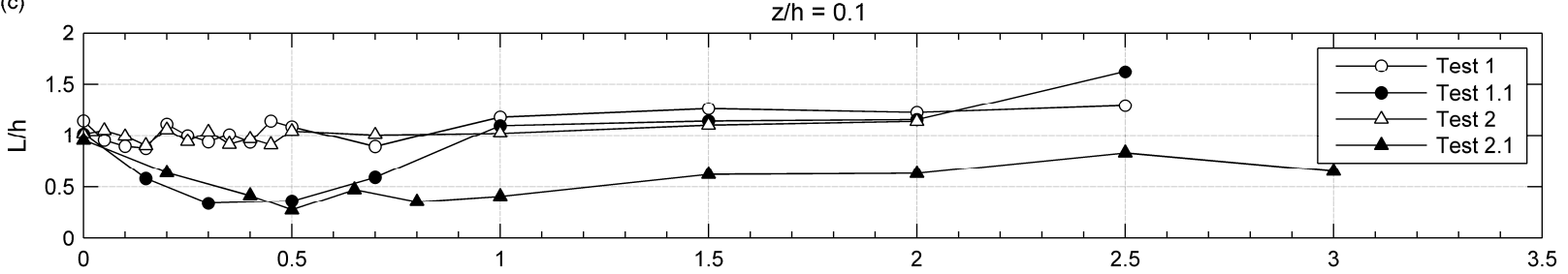

(d)

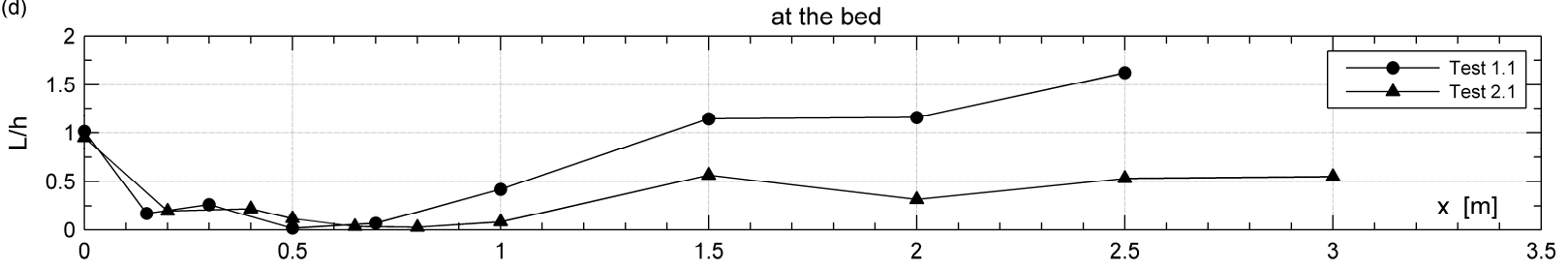

Fig. 7. Distributions of streamwise relative sizes of macroeddies on length of stream after the hydraulic jump over the non-eroded bed (tests 1 and 2) and over the scour hole (tests 1.1 and 2.1).

scour hole (tests 1.1 and 2.1). In tests 1 and 2 at water surface $(z / h=0.9)$ sizes of macroeddies almost did not change with the distance, whereas they increased in the middle zones of the stream $(z / h=0.6)$. Near the flat bed $(z / h=0.1)$, at the beginning of the stream $(x=0 \div 0.5 \mathrm{~m})$, the sizes of macroeddies did not change, later increased. The biggest changes in the sizes of macroeddies, comparing to the tests (1 and 2$)$ over the noneroded bed, were present at the bed and at middle depths (Fig. 7). Upstream the maximum depth of the scour hole sizes decreased and downstream they tended to increase. At the water surface, the sizes of macroeddies almost did not change with the distance up to the point of the maximum depth at the scour hole, farther they increased, while from the end of the scoured reach they started declining. The most noticeable changes in sizes of macroeddies were present in test 1.1 with lower discharge rate, as the scouring was limited to a short section and did not affect the whole flume bed like in the test 2.1.

Intensive mixing of waters caused by the hydraulic jump had also a significant impact on the relative sizes of macroeddies and their distributions in depth and the distance. The most noticeable effects are seen on the depth near the water surface and at the distance just downstream the jump. All obtained values of relative sizes did not exceed 1.6 of the stream depth and are comparable with those found in the literature for open channels. In tests over the non-eroded bed the smallest values of relative sizes of macroeddies were present near the water surface and for tests with scoured bed near the water surface and also at the bed of the scour hole.

\section{CONCLUSION}

On the basis of measured instantaneous velocities after the hydraulic jump in the channel, turbulence intensity and the streamwise relative sizes of macroeddies were analyzed. The results for the stream downstream of the hydraulic jump for the flat non-eroded and scoured beds are presented. The effect of the hydraulic jump is considerably high and it influences most of the turbulence characteristics in the channel.

Intensive mixing of waters being an effect of the hydraulic jump had a very large impact on the instantaneous velocity, turbulence intensity and sizes of macroeddies, as well as their vertical and longitudinal distributions in the stream. The impact of the water stream of the increased turbulence on the bed surface is the direct cause of formation of a scour hole downstream of water structures, which additionally affects flow characteristics. In the presented experiment, the biggest changes were present with the distance immediately downstream of the hydraulic jump, from the beginning of the scour hole to its maximum depth, while vertically near the water surface and above the bed of the beginning of the scour hole. Intensive mixing of waters caused by the hydraulic jump result in changes in the vertical distributions of relative sizes of macroeddies over the flat bed and over the scour hole, which are significantly different from the types of distributions in open channels. There are two regions about different vertical distributions over the bed of the scour hole, the first from the beginning of the scour to the maximum depth point and the second further. The study revealed that the size of the scour hole increases with the 
discharge and in the result location of the maximum scour depth is also changing. The vertical velocity also depends on discharge, rising with its increase. However, turbulence intensities $u$ ', sizes of macroeddies $L$ and relative sizes of macroeddies $L / h$ remain almost the same for different discharges in tests 1.1 and 2.1 .

In the measurement points farthest from the jump, obtained values of turbulence intensity decreased to the range of 0.03 to $0.15 \mathrm{~m} / \mathrm{s}$, which corresponds to the values found in the literature for the open channels with free flow conditions. Experiments revealed that the created scour hole caused only a minor reduction in the values of turbulence intensities in measurement points downstream the hole. Calculated values of relative sizes of macroeddies did not exceed 1.6 of the stream depth and are similar to those reported in the literature for open channels. Directly downstream of the hydraulic jump the scour hole triggered formation of small scale eddies.

\section{REFERENCES}

Ali, H.M., Gendy, M.M.E., Mirdan, A.M.H., Ali, A.A.M., Abdelhaleem, F.S.F., 2014. Minimizing downstream scour due to submerged hydraulic jump using corrugated aprons. Ain Shams Engineering Journal, 5, 4, 1059-1069. DOI: 10.1016/j.asej.2014.07.007.

Buffin-Bélanger, T., Roy, A.G., 2005. $1 \mathrm{~min}$ in the life of a river: Selecting the optimal record length for the measurement of turbulence in fluvial boundary layers. Geomorphology, 68, 1-2, 77-94. DOI: 10.1016/j.geomorph.2004.09.032.

Czernuszenko, W., Holley, E.R., 2007. Open-channel turbulence measurements with a three-component acoustic Doppler velocimeter. Publs. Inst. Geophys. Pol. Acad. Sc., E-7 (401).

Czernuszenko, W., Lebiecki, P., 1980. Turbulent characteristics of stream in open channel. Archiwum Hydrotechniki, 27, 1, 19-38. (In Polish.)

Czernuszenko, W., Kozioł, A.P., Rowiński, P.M., 2007. Measurements of 3D turbulence structure in a compound channel. Arch. Hydroeng. Environ. Mech., 54, 1, 3-21. (In Polish.)

Dargahi, B., 2003. Scour development downstream of a spillway. J. Hydraul. Res., 41, 417-426. DOI: 10.1080/00221680309499986.

Franca, M.J., Brocchini, M., 2015. Turbulence in Rivers. In Rivers-Physical, Fluvial and Environmental Processes. Springer International Publishing, pp. 51-78. DOI: 10.1007/978-3-319-17719-9_2.

Grinvald, D.I., Nikora, V.I. Hydrometeoizdat, Leningrad, Russia.

Kališ, J., 1961. Diminution de la turbulence derriere le ressaut. In: Rapport 111 IX Congres de IAHR, Dubrovnik.

Kozioł, A.P., 2000. Longitudinal sizes of the largest eddies in the compound channel. Prz. Nauk. Wydz. Inż. Kształt. Środow., 18, 151-159. (In Polish.)

Kozioł, A.P., 2008. Investigation of the time and spatial macroscale of turbulence in a compound channel. Acta Scientiarum Polonorum - Architectura, 7, 4, 15-23. (In Polish.)

Kozioł, A.P., 2012. The Kolmogorov's microscale eddies in a compound channel. Ann. Warsaw Univ. of Life Sci. SGGW, Land Reclam., 44, 2, 121-132.

Koziol, A.P., 2013. Three-dimensional turbulence intensity in a compound channel. J. Hydraul. Eng., 139, 8, 852-864. DOI: 10.1061/(ASCE)HY.1943-7900.0000739.
Kozioł, A.P., 2015. Scales of turbulent eddies in a compound channel. Acta Geophys., 63, 2, 514-32. DOI: 10.2478/s11600-014-0247-0.

Kozioł, A.P., Kubrak, J., 2015. Measurements of Turbulence Structure in a Compound Channel. In: Rowiński, P., Radecki-Pawlik, A. (Eds.): Rivers - Physical, Fluvial and Environmental Processes, GeoPlanet. Earth and Planetary Sciences. Springer International Publishing Switzerland, pp. 229-254. DOI: 10.1007/978-3-319-17719-9_10.

Kozioł, A., Urbański, J., Kiczko, A., Krukowski, K., Siwicki, P., 2016. Turbulent intensity and scales of turbulence after hydraulic jump in rectangular channel. Ann. Warsaw Univ. Life Sci. - SGGW, Land Reclam., 48, 2, 99-109. DOI: 10.1515/sggw-2016-0008.

Kumin, D.I., 1956. Turbulentnost i gaszenie energii pri sopraženi b'efow. 55th ed. Izviestia VNIIG.

Liu, M., Rajaratnam, N., Zhu, D.Z., 2004. Turbulence Structure of Hydraulic Jumps of Low Froude Numbers. J. Hydraul. Eng., 130, 6, 511-520. http://dx.doi.org/10.1061/(ASCE)07339429(2004)130:6(511).

Mazurczyk, A., 2007. Scales of turbulence in compound channels withtrees on floodplains. Publs. Inst. Geophys. Pol. Acad. Sc., E-6(390), 1-8.

McLean, S.R., Smith, J.D., 1979. Turbulence measurements in the boundary layer over a sand wave field. J. Geophys. Res., $84,12,7791-7808$.

Nezu, I., Nakagawa, H., 1993. Turbulence in Open-Channel Flows. IAHR Monograph. Balkema, Rotterdam, The Netherlands, 1-281.

Nikora, V.I., 1985. On the turbulence structure of river flows with sandwave bottom. Meteorol. Gidrol., 6, 98-103.

Nikora, V.I., 2007. 3 Hydrodynamics of gravel-bed rivers: scale issues. Dev Earth Surf Process, 11, 61-81.

Nikora, V.I., Smart, G.M., 1997. Turbulence characteristics of New Zealand gravel-bed rivers. J. Hydraul. Eng., 123, 9, 764-773. DOI: 10.1061/(ASCE)0733-9429(1997)123:9(764).

Nikora, V.I., Rowiński, P., Sukhodolov, A., Krasuski, D., 1994. Structure of river turbulence behind warm-water discharge. J. Hydraul. Eng., 120, 2, 191-208. DOI: 10.1061/(ASCE)0733-9429(1994)120:2(191).

Oliveto, G., Comuniello, V., 2009. Local scour downstream of positive-step stilling basins. J. Hydraul Eng., 135, 10, 846-851. DOI: 10.1061/(ASCE)HY.1943-7900.0000078.

Oliveto, G., Comuniello, V., Bulbule, T., 2011. Timedependent local scour downstream of positive-step stilling basins. J. Hydraul Res., 49, 1, 105-112. DOI: 10.1080/00221686.2010.538593.

Pagliara, S., Palermo, M., 2013. Rock grade control structures and stepped gabion weirs: Scour analysis and flow features. Acta Geophys., 61, 1, 126-150. DOI: 10.2478/s11600-0120066-0.

Pagliara, S., Lotti, I., Palermo, M., 2008. Hydraulic jump on rough bed of stream rehabilitation structures. Journal of Hydro-Environment Research, 2, 1, 29-38. DOI: 10.1016/j.jher.2008.06.001.

Rowiński, P.M., Mazurczyk, A., 2006. Turbulent characteristics of flows through emergent vegetation. In: Ferreira, R., Alves, E., Leal, J., Cardoso, A. (Eds.): River Flow 2006. Taylor \& Francis Group, London.

Rowiński, P., Czernuszenko, W., Kozioł, A.P., Kuśmierczuk, K., Kubrak, J., 1998. Longitudinal turbulence characteristics in a compound channel under various roughness conditions. In: Proc. 3rd Int. Conf. on Hydro-Science and -Engineering, Cottbus/Berlin, Germany. 
Rowiński, P.M., Czernuszenko, W., Kozioł, A.P., Kubrak, J., 2002. Properties of a streamwise turbulent flow field in an open two-stage channel. Arch. Hydroeng. Environ. Mech., 49, 2, 37-57.

Sanjou, M., Nezu, I., Suzuki, S., Itai, I., 2010. Turbulence structure of compound open-channel flows with one-line emergent vegetation. Journal of Hydrodynamics, Ser. B, 22, 5, 577-581. DOI: 10.1016/S1001-6058(09)60255-9.

Shiono, K., Knight, D.W., 1991. Turbulent open-channel flows with variable depth across the channel. J. Fluid Mech., 222, 617-646. DOI: 10.1017/S0022112091001246.

Siniscalchi, F., Nikora, V.I. Aberle, J., 2012. Plant patch hydrodynamics in streams: Mean flow, turbulence, and drag forces. Water Resour. Res., 48, 1, W01513. DOI: 10.1029/2011WR011050.

Urbański, J., 2006. Investigation of turbulence intensity of stream below hydraulic jump on the dam model. In: Problemy Hydrotechniki - Modelowanie i hydroinformatyka oraz wybrane zagadnienia ochrony przeciwpowodziowej. Dolnośląskie Wydawnictwo Edukacyjne, Wrocław, Poland, pp. 363-370. (In Polish.)

Urbański, J., 2008. Influence of turbulence of flow on sizes local scour on weir model. Acta Sci. Pol., 7, 2, 3-12. (In Polish.)

Urbański, J., 2010. Distributions of flow velocities on the length of local scour in downstream on weir model. Scientific Review - Engineering and Environmental Sciences, 47, 1, 34-42. (In Polish.)

Urbański, J., 2012. Verification of criteria for determining the length of bed protection in downstream of the weir. Scientific Review - Engineering and Environmental Sciences, 55, 55, 18-26. (In Polish.)

Wu, S., Rajaratnam, N., 1996. Transition from hydraulic jump to open channel flow. J. Hydraul. Eng., 122, 9, 526-528. DOI: 10.1061/(ASCE)0733-9429(1996)122:9(526).

Yokosi, S., 1967. The structure of river turbulence. Bull. Dis. Prev. Res. Inst., Kyoto, Japan, 17, 2, 1-29.

\section{NOMENCLATURE}

$a[\mathrm{~m}] \quad$ gate opening

$b[\mathrm{~m}] \quad$ width of flume at cross section

$d_{50}[\mathrm{~m}] \quad$ grain size diameter

$\mathrm{F}_{\mathrm{r}}[-] \quad$ Froude number

$g\left[\mathrm{~m} / \mathrm{s}^{2}\right] \quad$ acceleration due to gravity

$H[\mathrm{~m}] \quad$ upstream depth

$h[\mathrm{~m}] \quad$ depth in a measuring vertical over a sand bed after a sluice gate model

$h^{\prime}[\mathrm{m}] \quad$ tailwater depth

$h_{l}[\mathrm{~m}] \quad$ supercritical depth

$h_{2}[\mathrm{~m}] \quad$ subcritical depth

$L[\mathrm{~m}] \quad$ spatial turbulence macroscale

$Q[1 / \mathrm{s}] \quad$ discharge

$R(t)[-] \quad$ autocorrelation functions

$T_{E}[\mathrm{~s}] \quad$ temporal turbulence macroscale

$t[\mathrm{~s}] \quad$ times of scour

$U[\mathrm{~m} / \mathrm{s}] \quad$ time-averaged velocities in $x$-direction

$U_{a}[\mathrm{~m} / \mathrm{s}] \quad$ mean velocity (supercritical) at the sluice gate opening height $(a)$

$u_{i}, v_{i}, w_{i}[\mathrm{~m} / \mathrm{s}]$ fluctuating velocity in streamwise, lateral, and vertical coordinates, respectively

$u^{\prime}, v^{\prime}, w^{\prime}[\mathrm{m} / \mathrm{s}]$ turbulence intensity in streamwise, lateral, and vertical coordinates, respectively

$x[\mathrm{~m}] \quad$ distance from the stilling basin end to a measuring vertical

$z$ [m] distance from measurement point to the bed surface

$\sigma[-] \quad$ sediment gradation coefficient

Received 23 February 2016 Accepted 25 November 2016 